
\title{
3 Research Square \\ Quantifying End User Computing Device Use Phase Greenhouse Gas Emissions Using Analytics Software
}

Justin Sutton-Parker ( $\square$ Justin.Sutton-Parker@warwick.ac.uk)

University of Warwick https://orcid.org/0000-0001-8208-3644

\section{Research Article}

Keywords: Use phase energy consumption, Life cycle inventory, Computing scope 2 greenhouse gas emissions, Sustainable end user computing, Energy saving products, Computing carbon footprints, Computing life cycle assessment

Posted Date: November 3rd, 2021

DOI: https://doi.org/10.21203/rs.3.rs-893198/v1

License: (a) (i) This work is licensed under a Creative Commons Attribution 4.0 International License. Read Full License 


\section{Abstract}

\subsection{Purpose}

The purpose of this research is to answer the question, 'can end user computing (EUC) use phase electricity (UPE) consumption data be captured using analytics software regardless of location?' In doing so, the field experiment tests a proposed methodology that both addresses current barriers such as mobility and scale (Greenblatt et al., 2013) that limit the availability of EUC UPE field data (Karpagam \& Yung, 2017) and challenges current methodologies that cause concomitant greenhouse gas (GHG) emissions quantification to be inaccurate by $-48 \%$ to $+107 \%$ (Sutton-Parker, 2020).

\subsection{Methods}

This is achieved by using a distributed node based analytics software to capture both asset and use profile data sets from one hundred and eleven computer users operating in a subject organisation for 30days. The values are then used to populate the current and popularised UPE consumption calculation data flow (Kawamoto et al, 2001; Roth eta al. 2002) in order to examine for omissions. To test for accuracy, the EUC UPE consumption of one control subject is measured using both a watt-metre and the analytics software. The rationale being that the watt-metre data is extensively proven to be accurate (Energy Star, 2017) and will therefore expose errors produced by the software in relation to power draw, on-time and resulting kilo-watt hours $(\mathrm{kWh})$ values.

\subsection{Results and discussion}

Further to the data capture period, the findings are mixed. Positively, the new method reduces complexity via the ability to compile both data sets with one tool rather than a combination of two, such as asset management and watt-metre measurement. Specifically, scale and mobility issues are overcome, also allowing for location to be deduced and therefore national electricity conversion factors to be applied when calculating scope 2 emissions. Additionally, the current methodology error range is reduced from $155 \%$ (Sutton-Parker, 2020) to $48 \%$. Negatively, data omissions are experienced although surmountable,

with the exception of monitors being excluded from the capture process. This is due to the node requiring an operating system to collect data.

\subsection{Conclusion}

Whilst the research question is answered, the identification of energy consumption over reporting causes the analytics methodology to be arguably in need of further development. The rationale being that UPE consumption quantification is key to lifecycle assessment (LCA) and GHG accounting protocol and both require accuracy (WBCSD and WRI, 2004). It is therefore recommended that further research be undertaken to specifically address omissions and to reduce the over reporting aspect identified as caused by algorithms in the software used to calculate hardware power draw. 


\section{Introduction}

Since the Industrial Revolution, human polluting activity known as anthropogenic interference has already caused $1.0^{\circ} \mathrm{C}$ of global warming (IPCC, 2019). A further increase to $1.5^{\circ} \mathrm{C}$ will be reached between 2030 and 2052 if emissions increases continue at the current rate (IPCC, 2018). However, scientists calculate that reaching and sustaining net zero global anthropogenic carbon dioxide $\left(\mathrm{CO}_{2}\right)$ emissions by mid-century, will halt global warming on a multi-decadal scale and temperature gains will begin to peak (IPCC, 2018). To achieve this goal, it is calculated that the world cannot rely solely on key greenhouse gas abatement strategies, such as vehicle electrification and renewable energy transition (Dft, 2019a \& b, IEA, 2019, UNEP, 2019). This is because evidence indicates that the rapidity of adoption and associated abatement will not be sufficient to bridge the projected $32 \mathrm{GtCO}_{2} \mathrm{e}$ annual emissions gap forecast for 2030 (UNEP, 2019). As an alternative, scientists and governments agree that all aspects of human pollutant activity must be examined and low carbon alternatives researched and diffused during the next decade to compensate for this limitation (IPCC, 2018). Specifically, the United Nations Environmental Programme (UNEP) suggests that to bridge the gap, the world must combine existing technology with innovation to drive behavioural changes capable of reducing societal emissions (UNEP, 2019).

Considering the criteria, this research proposes personal computing as a candidate technology for participation in this alternate strategy. The rational being that as a mature technology, end user computing (EUC) generates in excess 1\% of global GHG annual emissions (Andraea and Edler, 2015; Bekaroo et al., 2014; Belkhir and Elmeligi, 2017; GeSI, 2008, 2012, 2015, 2019; Malmodin et al., 2013) and represents a rich source of pollution abatement. This pollution is caused by the yearly manufacturing of 460 million devices (Gartner, 2021; Statistica, 2020 and 2021) and the associated energy consumed by 4.2bn active users (Datareportal, 2021) (IEA, 2021a). In context this is equal to annual pre pandemic aviation emissions (IEA, 2021b). The emissions are generated by four phases of the EUC product lifecycle including embodiment, transportation, use phase energy (UPE) consumption and disposal. Transport and waste emissions contributions are consistent, producing 5\% and 1\% respectively (Apple, 2021; Dell, 2021; HP, 2021; Lenovo, 2021; Microsoft, 2021). Consequently, life cycle assessment (LCA) research indicates that the total carbon footprint of EUC devices is predominantly generated by the embodied and use phase emissions (Andrae and Andersen, 2010; Andre et al., 2019; Arushanyan et al., 2014; Subramanian and Yung, 2016). Whilst this is agreed, the proportionate representation of each value varies considerably between findings. As an example., the contribution of the embodied phase ranges from $12-97 \%$ and conversely use phase emissions from 3-88\% (Atlantic Consulting and IPU, 1998; Choi et al, 2006; Duan et al., 2008; Hart, 2016; IVF, 2007; Kemna et al., 2005; Kim et al., 2001; Lu et al., 2005; PE International, 2008; Sahni, S. et al., 2010; Socolof et al., 2005 and 2017; Tekawa et al., 1997; Teehan and Kandliker, 2012; Williams, 2004).

The incongruity is caused by four key variables, one attributed to the embodied emissions and three to the use phase emissions. The first being that whilst the lifecycle inventory (LCI) process is governed by international standard ISO2006 (Haque, 2020), embodied results variations are caused by differences in the way LCl data sources are calculated. As an example, values for metal, a key component of EUC device 
cases, fixings, wiring, chipsets, fans and hard drives, are subject to differing LCl quantification methods that either include or exclude the environmental influence of post-sales values such as exergy (Sonderegger et al., 2017; Steen, 2006). As such, depending on which database is accessed during calculation, the embodied value may change in prominence whilst remaining theoretically accurate (Finnveden et al., 2016; Peters and Weil, 2016; Rigamonti et al., 2016; Rorbech et al, 2014).

The second variable is caused by the annual kilowatt hour $(\mathrm{kWh})$ value attributed to the device. Unless specifically measured in the field with a watt metre, researchers and manufacturers predominantly rely upon two sources of data to determine the $\mathrm{kWh}$ value. If either source is inaccurate or not appropriate, then the proportionate representation of the UPE value will be affected. The first source is existing secondary field measured data. Whilst legacy sources from the late twentieth century exist in relative abundance, contemporary sources are recognised as highly limited (Greenblatt et al, 2013; Karpagam and Yung, 2017; Malmodin et al, 2010). As such, due to energy efficiency improvements (GeSI, 2008; McManus, 2002) EUC device UPE consumption quantification that relies upon legacy data will generate findings that are subject to a lack of specificity, obsolescence and extrapolation (Malmodin et al., 2010) thus reducing accuracy and validity. The recent limitation of available field data is due to $84 \%$ of devices now being mobile (Gartner, 2021; Statistica, 2020 and 2021) meaning that as people work from multiple locations daily (Gartner 2019,, traditional static watt metre measurement is unfeasible. Greenblatt et al. (2013) emphasise that consequently, widespread UPE field measurement is now avoided due to scale and mobility creating unsurmountable logistical complexities. Such is the limited availability of contemporary field data, Karpagam and Yung (2017) note that whilst conducting EUC device LCA comparison analysis their work was made all the more difficult by what is described as a field that is 'data starved'. Belkhir and Emeligi, (2018) concur, conceding that EUC UPE consumption findings are subject to error as validity of use profile variations is sought from sources predominantly tied to the desktop era between 1988 to 2002 (Norford et al, 1988; Koomey et al. 1995, Kunz, 1997, Komor, 1997, Hosni, Jones, and Xu, 1999, Roth et al., 2002). Intellect (2016) consequently echo Malmodin's (2010) concerns concluding that using legacy source data to calculate modern day EUC emissions is unreliable due to data being obsolete.

To compensate for the recent limitation, a second source of UPE consumption data offers a contemporary baseline value in the form of pre-sale energy efficiency Energy Star benchmarks (Energy Star, 2021). Conducted under strict test set up and conduct regulations, the programme accurately measures newly manufactured EUC devices for power draw in no-user present operational modes such off, sleep and idle (Energy Star, 2017). The results are published online (Energy Star, 2021) and include a typical energy consumption (TEC) value to represent an anticipated annual kilo-watt hours (kWh) value. Whilst used as the basis for manufacturer carbon footprint publications the values are ultimately without validity in the context of an LCA as they do not include the active operation mode when a user is interacting with the device. Research determines (Sutton-Parker, 2020) that this causes the TEC value to be inappropriate as a substitute for EUC UPE consumption field measurements as the additional power required as the device carries out useful work is excluded from any calculations (Sutton-Parker, 2020). Specifically, the inaccuracy ranges from $-48 \%$ to $+107 \%$ (Sutton-Parker, 2020) consequently causing LCI 
calculations reliant upon the TEC method to under estimate the proportionate representation of EUC UPE consumption by an average of $30 \%$.

The third variable is arguably simple, in the fact that the incongruity relates to the number of years of energy consumption included within the final LCA. The rationale being that including five years as opposed to three years of energy consumption will affect the UPE contribution by $40 \%$. As an example, when preparing product carbon footprint reports the world's five largest EUC device suppliers (Gartner, 2021) include various duration including 3-years (Microsoft, 2021), 4-years (Apple, 2021; Dell, 2021; HP, 2021) and 5-years (Lenovo, 2021). The lack of uniformity is driven by consensus of opinion not delivering specificity. As such, prevailing research determines that the initial 'first use' retention period has an average duration of between three and five years (Hart, 2016; Prakash et al., 2016; Thiébaud et al., 2017; Teehan and Kandliker, 2012; Williams and Hatanaka, 2005). This is predominantly influenced by factors such as company asset management and depreciation accounting and refreshes forced by a necessity to keep pace with new applications (Boyd, 2012). Where a 'second use' exists, if the device is sold or repurposed rather than disposed of, then this additional retention period is between two and three years (Prakash et al., 2016; Thiébaud et al., 2017). Consequently, it is reasonable to conclude that the lifetime input for the use profile ranges from three years to eight years before disposal. However, extending the lifecycle beyond five years is subject to research opinions that suggest the diminishing efficiency performance undermines the sustainability case for displacement of new devices (Bakker et al., 2014; Boyd, 2012, Cooper and Gutowski, 2017; Deng et al., 2011; Prakash et al., 2016; Schiscke et al., 2003; Vadenbo et al., 2017; Wolf et al., 2010). Consequently, similar to the embodied methodologies, selecting one duration over another remains theoretically accurate yet highly inconsistent.

The final variable affecting the GHG emissions generated by the determined UPE consumption value is the location in which the electricity is consumed. $\mathrm{CO}_{2} \mathrm{e}$ is the accounting unit that represents a unified value for all of the greenhouse gases (WBCSD and WRI, 2004). UPE consumption $\mathrm{CO}_{2} \mathrm{e}$ GHG emissions are calculated by multiplying the electricity consumed value $(\mathrm{kWh})$ by the $\mathrm{GHG}$ conversion factor published annually by each government where the energy is consumed (DoBEIS, 2021). The factor is created to reflect the carbon intensity of the electricity supply grid. EUC device manufacturers supply goods into regions with three different volts alternating current $(\mathrm{V} a c)$ electricity supplies including North America and Taiwan (115 V ac), Europe, Australia and New Zealand (230 V ac) and Japan (100 V ac) (Energy Star, 2017). As the 115 and $230 \mathrm{~V}$ ac are the largest, the relevant product carbon footprint reports are predominantly produced for one or the other depending on the brand (Apple, 2021; Dell, 2021; HP, 2021; Lenovo, 2021; Microsoft, 2021). The reality is that each country within a region will publish a different conversion factor based upon the carbon intensity included within the national supply grid (Carbon Footprint, 2020). The factors differ because all countries adopt renewable energy at different rates. Therefore, a country with a higher percentage of renewable energy supply will have a lower conversion value as it is producing less emissions per energy unit consumed. As an example the USA, which has been slow to transition to solar, wind and water source energy, has a conversion factor of 0.45322 (Carbon Footprint, 2020) compared to the UK factor of 0.21233 (DoBEIS, 2021). The difference 
being that for $10 \mathrm{kWh}$ of electricity consumed in the former will create $4.5 \mathrm{kgCO} 2 \mathrm{e}$ compared to the latter of $2.1 \mathrm{kgCO}_{2} \mathrm{e}$. Consequently, any LCA research or quantification relying directly upon manufacturer supplied UPE GHG data sources may over or under emphasise the value due to the impact of location.

Whilst the issue of embodied emissions incongruity is beyond the scope of this research, previous research designed to address key issues such as scale and mobility affecting the accuracy of EUC UPE consumption values have been undertaken. Notably, in response to increasing legislation and policy to reduce scope 2 emissions in the public sector, Cartledge (2008) and Hopkison et al (2009) produced the SustIT/JISC tool. Essentially an EUC device specific version of the UPE consumption input tables from Kenma et al (2005) LCA energy consumption calculator, the tool enables any organisation wishing to complete EUC use phase emissions quantification to do so following a few simple steps. First the organisation simply conducts an asset profile exercise and then inputs the high level results (e.g. $20 \mathrm{x}$ notebooks) into the tool. Using the TEC use profile formula, the researchers create a type (e.g. notebook or desktop) relevant use profile based upon energy measurements conducted within the relevant universities where the research was conducted. The resulting value is then multiplied by the relevant carbon emissions factor and $\mathrm{a} \mathrm{kgCO}_{2} \mathrm{e}$ unit value is produced. Whilst logical, again the limitation of the imposed use profile based upon a fixed seventy active hours per week may address the inclusion of an active value, it does introduce error of non-specificity raised by Malmodin et al (2010). The issue lies within the uniform UPE consumption value applied to device types (e.g. notebooks) rather than the specific notebook used by an organisation. As an example, the field measured annual electricity consumption in the workplace for a Chromebook illustrated previously is $11.93 \mathrm{kWh}$ (Sutton-Parker, 2020) generating 2.53 $\mathrm{kgCO}_{2} \mathrm{e}$ of annual scope 2 emissions if used in the UK (DoBEIS, 2021). Conducting the same calculation using the estimation tool (Hopkison et al, 2009) as the Acer device is categorised as a notebook, an average electricity consumed value of $30 \mathrm{kWh}$ is applied (JISC, 2019). This value is translated to scope 2 GHG emissions of $6.37 \mathrm{kgCO}_{2}$ e per device. As such, the inaccuracy introduced is equal to $+152 \%$. To overcome both non-specificity and mobility barriers software has previously been trialled to achieve the similar action of a watt metre based upon the simple rationale that in this form the 'measuring component' can simply move with the EUC device. The approach was called Joulemeter (Kansell, 2010) and was capable of measuring and reporting real time energy consumption of both physical IT hardware, virtual machines (VM) and software applications. Whilst the idea of moving to software based measurement would have offered scope for wide scale EUC device UPE consumption data to be generated, the tool suffered a setback for two reasons. Firstly, it required a watt meter for a calibration phase, thus re-introducing the issue it was designed to overcome plus upon scrutiny (Bekaroo et al, 2014) it proved to only achieve $59 \%$ accuracy. Subsequently, the software failed to progress and is noted only by Microsoft as no longer publicly available and deprecated. Consequently, to advance the concept of capturing EUC device UPE consumption values regardless of scale, mobility and location, and ultimately improve the availability of associated field data, this research uses analytics to capture both asset and use profile data. As such the following sections describe the methodology used to conduct the field experiment and the results and discussion generated by the undertaking. 


\section{Methodology}

The objective of the experiment is twofold. Firstly, to test the feasibility of using analytics software to capture both asset and use profile data regardless of scale, mobility and location. Secondly, to measure the accuracy of the resulting UPE consumption values. To achieve this the following structure is used:

- Identify a candidate organisation

- Identify a control subject

- Determine a suitable time horizon

- Determine a test set up and conduct

- Measure the organisation and control subject using the analytics software for the determined duration

- Document the results

- Discuss the results

- Summarise and conclude

- Make recommendations and state limitations

\subsection{Selecting the subject organisation}

Three considerations influenced the selection of the subject organisation. Firstly, at least mobile users were required to test the capability of the software in relation to scale and mobility. Secondly, operations within multiple countries was preferable to enable location capture to support the feasibility of identifying national based GHG conversion factors. Thirdly, a company already using the software for its intended use of digital experience management to avoid reluctance or delay related to the installation of new software that may be perceived as an unplanned cost or network security issue. To meet the criteria, the analytics software vendor was contacted and asked if they could propose a customer willing to participate in the research. The rationale being that Lakeside has over three thousand active customers and the likelihood of a positive response was high. Perhaps surprisingly, Lakeside themselves agreed to be the test organisation as they obviously use the analytics software as part of their business operations and were highly interested in exploring sustainability options both internally and to promote to customers. The profile of the candidate organisation subsequently met all proposed criteria.

\subsection{Time horizon}

The time horizon of the experiment is thirty days. This is determined by certain predefined reporting aspects built into the analytics software that offers both a daily and monthly cumulative report. Additionally, 30 days represents one month and as such can be extrapolated during the results and discussion to create annual values. 


\subsection{Test set up and conduct for the organisation}

The test setup was relatively simple as Lakeside already use the analytics software and as such analytic database nodes resident on the EUC devices were pre-installed and already collecting the required data at ten second intervals. To ensure that the asset and use profile data inputs identified as critical to the UPE consumption and concomitant GHG quantification were captured, a specific dashboard was created within the software's visualizer capability. As such, data sets including computer name, device manufacturer, model, serial, chassis format and age, power average in watts, energy consumption in kilo watt hours $(\mathrm{kWh})$, on time observed, and location were able to be extracted at the end of the 30-day period. The format is a simple Microsoft .xls Excel binary file.

The conduct for the main body of users required no intervention or awareness to ensure that the automatically captured data reflected the extraneous variables such as a multitude of unique user profiles experienced in a real life setting. However, as the control user was required to adhere to certain conditions to ensure comparison between the active time and watt metre readings, the following approach was employed.

\subsection{Test set up and conduct for the control user}

The control user was a single mobile user measured by both the analytics software and an accurate watt meter for use profile values to enable future comparison of results. Similar to the main cohort of users, the software was previously loaded and automatically reporting whereas the watt metre required specific set up. To ensure that the notebook energy consumption measured by the watt meter was not altered by any additional power demands such as plug sharing or peripheral devices, elements of the Energy Star benchmarking test set up (Energy Star, 2017) were incorporated in the test set up. These include:

A. The 'Input Power' using alternating current (AC) mains supply must be connected to a voltage source appropriate for the intended market (country). In this case the United Kingdom (UK) where nominal supply voltage is $230 \mathrm{~V}+10 \% /-6 \%$ to accommodate transformer settings of $240 \mathrm{~V}$

B. Connected to a watt meter meeting the IEC 62301 standards plugged in between the input power and the mains supply.

C. No peripheral devices were used or attached during the experiment

D. The notebook was connected to the power source for 24 hours per day for the duration of the experiment

To safeguard that the notebook energy consumption measured by the software was not affected by the loss of Wi-Fi signal during the experiment a local area networking (LAN) cable was connected directly to the broadband router via the Ethernet port. It was confirmed by the software vendor that the network interface card (NIC) is included in power monitoring. The notebook was operated by one consistent user throughout. To mirror real world use, no restrictions were placed upon when the notebook could be used 
during each twenty-four-hour measurement period with the exception noted below. As both the watt meter and software are capable of measuring the time per day that the notebook is 'on' and drawing energy the following modes were measured.

A. 'On Time' representing the period of time in hours and minutes that the notebook was 'on' and drawing electricity. This is not to be confused with the 'active' measurement used in experiment 2 as it also includes periods of time when the notebook has transitioned to other modes such as short or long idle.

B. 'Off' representing the period of time that the notebook was either switched off or had powered down and was potentially no longer drawing energy.

To enable comparison to existing TEC and active use comparative research, Energy Star recommendations were used for most part of the experiment as follows:

C. Display Sleep Mode was to initiate after 15 minutes of user inactivity as per Energy Star recommendations.

D. Sleep mode was set to initiate after 20 minutes of user inactivity as per Energy Star recommendations.

Deviations to this test set up were included in the experiment on certain days to test the capability and accuracy of the software. These included changing the power settings for the device to disable the sleep and/or 'turn off the display function'. The rationale was to test if certain aspects of the software required the user to be actively logged in and working for energy consumption reporting to occur. This is explained in full in the results discussion.

Whilst the software data collection is automated the watt meter daily energy consumption $(\mathrm{kWh})$ values and on time (hours and minutes) were noted manually from the LCD screen at the same time to maintain consistency.

\section{Results And Discussion}

The results are categorised and discussed in two categories of feasibility and accuracy. As such the following sections firstly document the ability of the analytics software to capture asset and use profile data in relation to the majority of users, before discussing the accuracy of the use profile data as determined by the control user.

\subsection{Feasibility testing asset and use profile data capture}

The data flow created by Kawamoto et al (2001) and refined by Roth et al (2002) defines inputs required to calculate the UPE consumption of computer device types within large install bases such as companies, sectors and geographies. Effectively the model creates two data sets called asset profile data and use profile data. The first data set determines the types and number of devices used by various user types to create a stock unit quantity. The second captures user usage time and computer power demand in watts 
to calculate a unit energy consumption (UEC) value. The two values are then multiplied by one another to create a total EUC device UPE consumption value. As an example, Fig. 1 shows the data flow utilised to enable the kWh consumption quantification of all EUC devices within a University. In this instance the educational establishment is able to not only understand the total energy consumption caused by devices such as notebooks, tablets and desktop computers but also sources of specific consumption such as student or staff notebooks (see comparison in results section).

Simplified, the calculation flow is represented by the equation Asset Profile (units) $x$ Use Profile $(\mathrm{kWh})=$ Total Use Phase Energy Consumption (kWh). Consequently, in order to accurately quantify EUC device UPE consumption values required for scope $2 \mathrm{GHG}$ emissions calculation, the analytics software must capture the following data:

- Asset profile data - quantity (unit), type (description), model (description) and user (description)

- Use profile data - power draw (watts), usage (hours and minutes)

Whilst the asset profile data is self-explanatory, the use profile data arguably requires explanation as to how the quantification of watts and time produce $\mathrm{kWh}$. As such, the energy value $(\mathrm{kWh})$ is produced, as would be the case with any electrical item, by multiplying power (watts) supplied to the device by the length of time (hours) the device is used, divided by equivalent energy used by a 1,000W electrical device for one hour. As an example a $50 \mathrm{~W}$ personal computer (PC) would take 20 hours to consume $1 \mathrm{kWh}$. Therefore, the same 50W PC would consume 1.2kWh if left in operation for twenty-four hours. Consequently, measured energy in $\mathrm{kWh}$ is expressed as follows:

\section{$\mathrm{kWh}=\underline{\text { Watts }} \times$ Time $(\underline{\mathrm{hrs}})$}

1000

This input is of particular importance because whereby asset profile data is fixed for each device and can be collected by existing practices such as survey or asset inventory software, the use profile value is subject to extreme variation that differs even when comparing identical devices of the same model and manufacturer. This is because the value is highly influenced by the way in which the user interacts with the device. The rationale being that no two users will operate an EUC device for the same amount of time and to complete the exact same tasks during each year of the device useful lifespan. In relation to scope 2 use phase GHG emissions quantification, if the kWh value is not captured accurately, then despite the appropriate $\mathrm{GHG}$ electricity conversion being correct, when multiplied by the kWh result the $\mathrm{CO}_{2} \mathrm{e}$ value will ultimately also suffer inaccuracy.

As previously noted, the most accurate method of capturing the kWh value is achieved by placing a watt metre between the EUC device and power source. By doing so, all power draw (W) and duration of use (T) are captured in real time in order to produce the electricity consumption $(\mathrm{kWh})$ value. However, as previously noted, the two key issues preventing organisations undertaking such practices are scale (too many devices) and mobility (too many locations). This causes the avoidance of quantification of a source of emissions calculated to be responsible for at least $1 \%$ of global GHG emissions that could act 
as a source of abatement and assist with both mandatory emissions reporting and abatement and specific sustainable IT procurement policies in place in the USA, Europe and the UK. To overcome the two barriers, this research feasibility tests a newly proposed process using descriptive analytics software to accomplish the capture of both asset and use profile data. Using a distributed analytics software node installed on each EUC device, the inputs required to populate the UPE consumption data flow are captured in real time across over one hundred devices, regardless of location. Whilst overall the feasibility is proven, errors are experienced in relation to the completeness of the data including limited hardware descriptions, user identification alignment with devices and inaccurate power draw values.

In order to inspect the captured data, three separate reports within the digital experience monitoring solution were accessed including hardware (computer name, manufacturer, model, chassis), computer performance (computer name, user name, location) and power (computer name, power draw, kWh, on time). As noted in the methodology, to eradicate the complexity of cross referencing and possible introduction of error, a browser accessed dashboard was created within the software's visualizer function to isolate and display only the required data sets structured in an .xls format. In order to also ensure anonymity during the experiment, employee and computer names were intentionally obfuscated and replaced with alpha numeric sequenced descriptions (see Fig. 2).

\subsubsection{Asset profile data capture - quantity, type, model and user}

Documenting the exact quantity of devices by type, model and associated users represents the foundation data required to complete the capture of asset profile data. As highlighted by the discussed spreadsheet tool methodology previously, failure to produce device specific results generates inaccuracy. The original Kawamoto et al research utilised the calculation flow to calculate the number of devices in operation at a national scale generating stock unit quantities for residential, commercial and industrial computer installations. As the asset capture is undertaken within a single company, the market input is replaced with a job role. The rationale being that when examining identified areas of high EUC device energy consumption and therefore concomitant GHG emissions, an organisation is enabled to understand if it is a job role causing excessive on time as an example. Additionally, to ensure appropriate national electricity conversion factors can be applied, an additional input of location is captured by the software.

Further to the data capture period, the analytics software collected asset profile data from all one hundred and eleven end user devices. In relation to type, seven manufacturers were noted, consisting a total of forty-six different models of EUC devices. Notably, no categorisation was achieved for $10 \%$ of devices, with a further $4.5 \%$ being tablets, $10 \%$ desktops and $75.5 \%$ notebooks. As demonstrated in the use profile section, type is vital to the data flow as a notebook will have a very different power draw to a desktop computer. The user role identified 17 sales people, 6 corporate workers, 1 professional services consultant, 7 technical support representatives and 2 technical services engineers. As such, $78(70 \%)$ of employees were simply listed as 'not collected'. Location was captured successfully in 90 instances 
across eight countries with 23 entries registered as 'not collected'. Of the captured location data, $43 \%$ were based in the USA, $26 \%$ in the UK, $10 \%$ in India, $2.2 \%$ in each of the Netherlands, Poland, and the United Arab Emirates and $0.9 \%$ in both Israel and South Africa.

Further to the findings it is notable that whilst asset data was captured for $100 \%$ of devices, the success rate of each metric suffered omissions. The $10 \%$ omission of type was discovered to be due to the software application programme interface (API) accessing basic meta-information from the Microsoft Windows Management Instrumentation (WMI) database. The WMI stores definitions of products to work in conjunction with the Windows Driver Model (WDM) to allow for update and management of the device by acting as a repository of software drivers, applications and extensions available in the Windows operating system (OS). As the inventory data populates automatically using the WMI data when the analytics agent is installed on the device, then the issue of type omission would require to be addressed within the WMI and is therefore arguably surmountable. The issue of only collecting $30 \%$ of job roles was defined as the role based attributed not being defined within the company's active directory.

Consequently, to improve accuracy simply updating the employee role details on the domain network would theoretically rectify the issue. Of location, no definite reason for $21 \%$ lacking in data although the hypothesis was suggested that users exhibiting this lack of granularity may be using internet protocol (IP) masking software therefore denying the function access to information identifying which country the device is being used in.

Whilst it is anticipated that each omission may be overcome with additional focus, to gauge if the proposed analytics approach represents an improvement to existing techniques, further asset profiling practices were undertaken at two different organisations using survey and asset management software. The survey technique was undertaken at the University of Sussex, having agreed to assist the research due to an interest in wanting to better understand the environmental impact of the current EUC estate with regards to use phase emissions. The technique proved highly time consuming from a creation process as it required sixty-eight specific questions to capture the required data via drop down, sliding scale and free type inputs. As the results were populated manually by the IT manager, there was no ability to identify location of devices and only hardware supplied by the University could be included. As an example it was not possible to account for any student owned devices used in the campus. However, further to completion of the survey online via a supplied quick response (QR) code, the results identified 8,927 end user computing devices and 20,000 light-emitting diode (LED) displays. By type the devices were noted as 5200 desktop computers, 1840 integrated desktop computers, 960 workstations, 927 notebooks and 20,000 monitors. Excluding the monitors, the EUC devices are dominated by $58 \%$ desktops, $21 \%$ integrated desktops, $11 \%$ fixed workstations and 10\% notebooks. Specifically, due to the prominence of monitors within the University estate, the survey technique highlighted that the analytics software failed to capture peripheral EUC devices. Upon further investigation, it was found that the initial analytics 'hardware' report includes a column indicating the number of monitors detected as connected to the device at any point during the measuring period rather than any associate make, model or size. Further to speaking with the analytics vendor it was explained that as the condensed SQL node requires an operating system to interface and as such reporting asset or power profile data for peripheral devices, 
such as monitors, was not achievable currently. Considering that 157 monitors are listed as connected to the devices profiled by the analytics software, the impact is significant as the resulting electricity consumption would be excluded from any calculations due to the lack of asset data. Comparing the two practices, each suffers setbacks. The survey technique lacks the automation of the analytics approach and cannot generate location context. Although positively, the ability to include peripheral devices is arguably essential for complete representation of use phase emissions. From a time to completion perspective, the lack of automation suffered by the survey method is partially passed on to the person tasked to populate the asset profile data as noted by the University IT manager:

'I think the survey was very easy generally. There were a couple of sections I had to go back over because I'd not appreciated the whole breakdown of areas so consolidated initially and then had to separate once I realised, but this wasn't bad and could be addressed by providing a list of the areas in advance. That would probably help anyway to be honest as there is a fair amount of info to gather which I happened to have but I'm guessing not everyone would.' - P. Collier, University of Sussex

The comment highlights however, that unless some form of asset list already exists then, unlike the analytics approach, the process may become unfeasible. Consequently, in order to offer an automated comparison to the analytics method, the same asset profile process was undertaken using automated asset management software at a prosthetic limb manufacturing company, Ossur. The company is an active participant in the United Nations Global Compact working towards sustainable and socially responsible goals and, similarly to the University, wished to assist the research in testing methodologies. As asset management software called Lan Sweeper was already installed at the company, a similar Microsoft Excel file extension spreadsheet was extracted using the software report structuring capability. As before, asset profile inputs such as quantity, manufacturer, model and location were generated with the exception of chassis (type) and role. This first exclusion was caused because the type of device, such as notebook, was not available within the report function as a criterion. To overcome this, a look up table was created to compare the captured device brand and model data with type data extracted from the Energy Star online data base. With regards to role, it is feasible within the software, although similar to the analytics software the function had not been configured at the active directory level. In order to overcome this in the short term, the captured location data was used to create role based context. Although not conclusive, this was achieved because each Ossur site has a specific function such as manufacturing and clinics. As such, a further lookup was created to generate a 'role' defined by location column including support, manufacturing and clinician. With the exception of the additionally created functions, unlike the survey method, the data extraction was instantaneous thus mirroring the time saving capabilities of the analytics solution. Arguably more importantly, the asset management software also identified peripheral devices such as monitors excluded by the analytics tool. Specifically, the asset management software method identified 3,928 EUC devices. Of these 30\% (1,160 units) were desktop computers, $67 \%$ (2,643 units) notebooks, $1 \%$ (43 units) integrated desktop computers and 2\% (82 units) workstations. A further 2,579 monitors were identified ranging from 14" mobile screens to 92 " presentation and information displays. From a role perspective, $20 \%$ of devices were used by prosthetic, bracing and supports business units, $20 \%$ by clinicians, $14 \%$ by manufacturing and operations, $5 \%$ by 
research and development with $41 \%$ unable to identify a specific role. Location data was captured for $97.5 \%$ of the devices with only 95 devices indicating neither region nor country. Proportionately, the devices were located 62\% in Europe, 32\% in the Americas, and 6\% in Asia and Pacifica.

Summarising the asset profile data capture capability of the analytics software it is reasonable to state that when compared to the existing methods of survey and asset management software it is certainly a more efficient approach in terms of time spent. Contrarily, it is also reasonable to suggest that having created the survey and the look up tables, this advantage diminishes when conducted for a second time. Undoubtedly, the survey method would fail if no prior records existed and as such the asset management software perhaps offers the ideal solution to populate the first half of the Kawamoto data flow. With regards to accuracy, to collect the key inputs of type, make, model, user and role analytics again outperforms both options from a granularity perspective by achieving the chassis categorisation and location without intervention. However, the oversight of not specifying peripherals such as monitors causes it to be highly flawed considering that such devices consume often higher electricity values annually than notebook devices. Specifically, in both cases of the University and the medical manufacturer monitors constituted $69 \%$ and $40 \%$ of all EUC devices respectively. Although arguably not always utilised by mobile device users operating notebooks and tablets within an organisation, considering too that fixed thin clients, desktop and workstations cannot operate without a monitor and represent $14 \%$ of all EUC devices manufactured, ignoring this category is not feasible if accuracy is sought.

\subsubsection{Use profile data capture - power draw, on time}

Unlike the survey methodology and asset management software practice, the analytics software has the ability to collect use profile data required to populate second half of the Kawamoto et al data flow. Leveraging a distributed database architecture that is stored on the endpoint, the software captures thousands of end-user data points at five second intervals. The results are transmitted by networking technologies for compilation by a Microsoft SQL database operated by a master server situated either onpremises at the organisation's data centre or in a cloud computing data centre. The graphical user interface offers a configurable dashboard that when configured, enables selected metrics to be displayed either in summary or by detail such as a single user device at any selected time. Among the available metrics, the power reporting function captures power draw (watts) per device and on time observed (hours and minutes) in order to generate a kilowatt hour ( $\mathrm{kWh}$ ) calculation. As discussed in the methodology, this capability is effectively mimicking the actions of a watt metre without the restriction of being bound to a static power source. Consequently, the use profile data captured for the subject organisation's devices is examined for completeness and tested for accuracy. Data quality assessment is achieved by ensuring the use profile data generated by the organisation's workforce is complete and where appropriate the kWh data can be converted to display location specific use phase GHG emissions. Whereas accuracy is validated using a single user as a control subject measured by both a watt metre and the analytics software's power capability. 
Data completeness was high with regards to capturing the use profile values as only $7 \%$ of devices were excluded. Examining these exclusions revealed that only the egress IP location had been captured suggesting that the device had been used at some point during the last year but not during the measurement period. The rationale being that this data is retained until refreshed. Whilst not confirmed in this specific case, this is may be because the devices are surplus stock awaiting assignment to new employees. Consequently, 103 devices reported power and on time observed metrics required to complete the electricity consumption $(\mathrm{kWh})$ calculation. The power draw is represented as a watt $(\mathrm{W})$ average value for the entire period. This ranged from $10 \mathrm{~W}$ registered by an Apple MacBook Pro notebook to $145 \mathrm{~W}$ for the HP EliteDesk 800 G5, which is a tower form factor desktop similar to a small server. This created an average power draw of $49 \mathrm{~W}$ for the entire EUC estate. The demand was elevated specifically by the desktop category, as would be anticipated due to the component architecture of the devices. As an example, the desktop power draw ranged from $59 \mathrm{~W}$ required by a small form factor HP EliteDesk $800 \mathrm{G} 1$, rising to the noted $145 \mathrm{~W}$, creating a desktop computer category average of $88 \mathrm{~W}$. Comparatively, the notebook estate ranged from the noted $10 \mathrm{~W}$ value to $93 \mathrm{~W}$ registered by a Dell Latitude 5285 convertible notebook. As such, the measured notebooks averaged 39.66W and 55\% lower than the desktop estate. Examining existing research [ref], the notebook values in particular appear relatively high adding emphasis to the examination of the control data discussed below.

The second metric of 'on time observed' is represented by a percentage of the 30 -day period that the software node registers the computer as being used. As such, a $10 \%$ on time reading means that the device is used for 72 hours during the available 720-hour measurement period. Consequently, if the average power draw is $10 \mathrm{~W}$, such a device would require $0.72 \mathrm{kWh}$ of electricity consumption for one month. As with the $\mathrm{W}$ value, all but eight devices registered on time ranging from $2.4 \%$ ( 1 hour 45 minutes) to $100 \%$ (720 hours). The average for all devices was $41.42 \%$ on time during the thirty-day measurement period. As the month in which the measurement occurred included twenty work days this result indicated that the employees were either spending an average of almost fifteen hours per working day operating devices or that other factors were influencing use. These include the possibility of shared use, additional leisure use such as streaming, standard power management settings such as sleep being overridden or software inaccuracy. As accuracy is investigated thoroughly by the control device and leisure time and power management are not tracked, shared use was examined. As such $10 \%$ of the devices exhibited between $90-100 \%$ on time raising the average value considerably. Of these devices, it was revealed that $64 \%$ were desktops operated by technical support in shifts that according to the organisation, enable the support team to action requests twenty-four hours per day.

Applying the power average to the on time in the manner previously discussed produces a total of 1,592 kWh electricity consumption by the EUC estate. Specifically, the data determines that eleven desktops representing just $10 \%$ of all devices consumed $41 \%$ ( $657 \mathrm{kWh}$ ) of the measured energy due to a combination of high W values and extended on time as discussed. Comparatively, one hundred notebooks representing $90 \%$ of the estate consumed $59 \%$ ( $935 \mathrm{kWh})$. By location the UK consumed the highest value of $699 \mathrm{kWh}$ (24 units), followed by the USA $585 \mathrm{kWh}$ (39 units), India $66 \mathrm{kWh}$ (9 units), Netherlands 29 kWh (2 units), Poland 19 kWh (2 units), the United Arab Emirates 23 kWh (2 units), Israel 
$21 \mathrm{kWh}(1 \mathrm{unit})$ and South Africa $13 \mathrm{kWh}$ (1 unit). The representation by country as displayed in Fig. 3 allows for visual comparison as to the importance of location when determining use phase emissions using national specific electricity conversion factors. Clearly whilst the use profile data determines the UK to be the highest consumer of electricity even though it has 14 less devices than the USA operations, in terms of actual emissions the USA proves to be the highest polluter. This is as previously described, due to less renewable energy being available in the US supply grid and therefore generating a higher carbon intensity of carbon per kWh consumed.

To summarise, with the exception of the surplus devices, use profile data capture using the proposed analytics methodology proved comprehensive. The key values of power (W) and use (hours and minutes) were captured successfully enabling concomitant GHG emissions values to be generated. As such it is reasonable to state that the analytics software achieved the same function as a watt metre whilst overcoming the barriers of scale and mobility. The rationale being that 103 devices were measured in near real time across 4 continents, 8 countries, with $90 \%$ of the devices being mobile. However, whilst the data is represented cohesively, if proven inaccurate then the advancement of technique is diminished. As such the next section examines accuracy via the control user results.

\subsection{Determining the accuracy of analytics software captured use profile data}

Following the completion of the 30-day measurement period the control user results indicate that the analytics software overestimates electricity consumption ( $\mathrm{kWh}$ ) by an average of $48 \%$. The range of error is between minus (+) $29-58 \%$ with minor anomalies of $-100 \%$ caused by long period of 'off mode'. At a summary level, the accurate watt metre measured $4.25 \mathrm{kWh}$ for the single device whereas the software measured $6.31 \mathrm{kWh}$ of electricity consumed. In order to determine the source of the disparity, the two measured values used to generate the kWh result are examined for inconsistency. As noted in the use profile capture section, these values are the time spent in operation and the power drawn $(\mathrm{W})$ during that period.

\subsubsection{On Time Observed}

As noted, 'on time' is defined as the period of time measured in hours and minutes that the notebook is registered as drawing power and therefore consuming energy. Due to the 30-day duration of the experiment the highest feasible on time would be 720 hours ( 30 days multiplied by 24 hours). On time represents one of the key values used to calculate a kWh value. The results highlight that the watt meter reported a total on time measurement of $44.3 \%$ or 318.95 hours during the 30 -day period. Comparatively, the software reported an on time of $40.8 \%$ or 293.76 hours. The results deliver an error of on time underreporting by the software of $-3.5 \%$ or -25.2 hours. Divided by the time horizon, this suggests that the software is not reporting electricity consumption for an average of close to 50 minutes per day. To identify the source of the on time inconsistency, data relating to 'off' and 'sleep' modes were examined. 
'Off Mode' is defined (ref) as when the power consumption level in the lowest power mode which cannot be switched off (influenced) by the user and that may persist for an indefinite time when the appliance is connected to the main electricity supply. In context, off mode is achieved when the user has shut down (not sleep mode) the notebook yet it remains plugged into the power source. In this state no 'on time' should be registered by either the watt meter or the software. The results indicated that the watt meter did not register any on time when the notebook was in off mode. It was however noted that a minimal draw of $0.005 \mathrm{kWh}$ was recorded for a 24-hour period. Reversing the $\mathrm{kWh}$ equation indicates that $0.2 \mathrm{~W}$ 'trickle feed' of electricity occurs when the notebook is in off mode as the battery experiences a minor energy discharge. The standard Energy Star TEC benchmarks are calculated with 'off mode' assumed as $25 \%$ of annual use profile. Using this mode weighting and the experiment results, the watt meter measured value would be $0.456 \mathrm{kwh}$ per annum. The official Energy Star published benchmark results for the HP Elite Book notebook is $0.2 \mathrm{~W}$ draw and $0.438 \mathrm{kWh}$. Consequently, the watt meter results confirm that the source is $100 \%$ accurate for reporting 'on time' in 'off mode' and $96 \%$ accurate with regards to kWh measurement when extrapolated and compared to the TEC benchmark [1].

Comparatively, the software also correctly measured no 'on time' when in the 'off mode'. However, it was noted that the software also measured no power draw nor energy consumed. The impact of the software not reporting 'off mode' electricity consumption creates an under reporting disparity ranging from zero to $2 \%$ maximum depending on the duration of 'off mode' weightings. As an example, the maximum off time that could be attributed to the experiment's measured 30 -day period is $55.7 \%$ or 16.7 days (401 hours). As such, the total energy not measured by the software in this instance is equal to $0.0835 \mathrm{kWh}$ or $1.9 \%$ of the total energy consumption measured. However, as the test set up and conduct methodology includes a requirement for the notebook to be placed into sleep by the Energy Star governed power settings, there is no influence to the results of this experiment. In relation to 'Time' reported during off mode, it is reasonable to state that both the software and watt meter are $100 \%$ accurate and therefore this metric does not contribute to the $48 \% \mathrm{kWh}$ disparity.

Having discounted 'off mode' as the source of error, the 'sleep mode' results were examined. 'Sleep Mode' is defined as a low power state that the computer is capable of entering automatically after a period of inactivity or by manual selection. As determined by the methodology the sleep mode was set to initiate automatically after 20 minutes for the predominant duration of the experiment. Exceptions did occur including setting the notebook to sleep instantly at night and as described below in order to test the software capability. The results indicated that the watt meter registered 90 minutes of on time during a 24-hour period when the notebook was in sleep mode consuming a maximum of $0.020 \mathrm{kWh}$ per full day. The standard Energy Star TEC benchmarks are calculated with 'sleep mode' assumed as 35\% of annual use profile. Using this mode weighting and the experiment results, the watt meter measured value would be $0.895 \mathrm{kwh}$ per annum. The official Energy Star published benchmark results for the HP Elite Book notebook (the equipment under test) is $0.3 \mathrm{~W}$ draw and $0.919 \mathrm{kWh}$. Consequently, the watt meter results confirm that the source is $97.4 \%$ accurate with regards to $\mathrm{kWh}$ measurement when extrapolated and compared to the TEC benchmark [1] and within the accepted $5 \%$ error range. 
Comparatively, the software measured zero 'on time' during sleep mode and no associated power draw nor electricity consumption causing it to be determined unresponsive and therefore inaccurate for all periods of time spent in sleep mode. As the on time registered by the software is $40.8 \%$ and the methodology dictates no 'off time', this finding indicates that the notebook entered sleep mode for a maximum of $59.2 \%$ of the experiment's duration. This time period is equal to 426 hours and 14 minutes. The watt meter indicated that for each hour the notebook spent in sleep mode 3.83 minutes were classified as on time as the notebook was drawing a minimal amount of energy. Combining the mode and duration values indicates that 26.64 hours of 'on time' has occurred but not been reported by the software due to sleep mode. Consequently, if the on time measured during sleep mode by the watt meter is added to the software on time reading, the result is 320.16 hours of on time and is correct to within $0.37 \%$ of the watt meter 'Time' reading. As such, it is reasonable to state that the time disparity between the two data sources has been identified and explained.

\subsubsection{Power Draw}

Whilst the difference between 'on time' values was satisfactorily addressed, the finding did not correct the $48 \%$ energy consumption $(\mathrm{kWh})$ disparity generated during the experiment. Contrarily, if the additional $\mathrm{kWh}$ generated by the extra on time generated by sleep mode $(0.1278 \mathrm{kWh})$ were added to the software results then the disparity would rise a further $3-51 \%$. As such, the second key value of power (W) was examined for inconsistency. Having determined that time reporting was consistent between sources to within an error of $-7.9 \%$, and that the watt metre was accurate within less than $3 \%$ compared to published TEC results, theoretically the over reporting error must be caused by inflated Watt readings. As Fig. 4 shows the kWh daily reading from both sources is relatively consistent in its disparity across all 30 days. Both data sets follow one another's peaks and troughs across the experiment's time horizon as content switching fluctuated the power draw as various components worked at varying paces. The only exceptions to this are shown on two weekends (days 21, 22 and 28,29) when the notebook was used for a very limited (and in some cases not at all) period. In these examples the sleep mode kWh reported by the watt metre exceeded the zero kWh noted by the software as previously validated. Consequently, it is clear that the power draw (W) is being over reported by the software by an average of $51 \%$ per day when the four anomalous days were excluded. The full range of error was between $+48 \%$ and $+58 \%$.

As the uniform disparity became obvious from the results generated in the first week a one-day test measure was introduced for the 8th day in the hope that the results generated might indicate to source of the error. As such, specific short term changes were introduced to the test set up and conduct. Specifically, for the duration of day 8 only, the power options on the notebook were altered from those described in the methodology to the following:

- Turn off display when plugged in = Never

- Put the computer to sleep $=$ Never

The rationale for the changes being that the notebook would remain in an apparent active work state for 24 hours even after the user interaction had ceased. The results would list both the power requirements 
during working hours when content switching occurred and during the time that the screen was left active but resting during non-working hours (when no content switching occurred). Consequently, anomalies during either active or resting on time period may offer clues to the problem. The results for day 8 highlighted that the as expected the on time reported by both the software and watt metre was exactly 24 hours and therefore correct. This further validated that the software is accurate with regards to on time measurement. During the 9 hours when the notebook experienced user interaction the kWh inaccuracy rose to $63 \%$. Comparatively, during the remaining 15-hour period of the notebook being active but without user interaction, the kWh inaccuracy was lessened with a disparity of $46 \%$ when compared to the watt metre readings. Examining the watt results for the inactive period revealed that the software recorded a near constant reading of $19 \mathrm{~W}$ whereas the watt metre recorded $13 \mathrm{~W}$. As such it is reasonable to state that when the notebook is in idle or long idle mode (represented by the inactive period) the software is uniformly inconsistent by $46 \%$. Examining the watt results for the active 9-hour period revealed that the software recorded a range of $19 \mathrm{~W}$ to $26 \mathrm{~W}$. Whereas the watt metre ranged from $13 \mathrm{~W}$ to $27 \mathrm{~W}$. At the lower end, the results reflected the inactive period results as expected. However, it was notable that the high end readings became almost equivalent in some instances. This suggested that either the frequency of measurement, changes in user tasks or a combination may be causing the issue. The rationale being that if the watt metre reports in real time then the equivalence may only last for one second yet could theoretically be measured by the software for a longer period causing a great disparity. Before examining the method of measurement used by both sources the impact of user tasks on the watt readings was examined (see Fig. 5). Both lowest and highest watt readings were noted during four tasks including logging on (powering on), resting (with applications open), productivity (email, documents, spreadsheets) and video conference calls. The watt meter exhibited as total range of $107 \%$ and the software $37 \%$ creating a difference of $70 \%$ range during the active period. Specifically, the two sources $\mathrm{L}$ to $\mathrm{H}$ readings ranged across the four tasks as follows:

1. Power On

a. Watt Metre $32 \%$

b. Software $24 \%$

2. Resting (Applications running)

a. Watt Metre $8 \%$

3. Productivity

b. Software $5 \%$

a. Watt Metre $57 \%$

b. Software $37 \%$

4. Video Conference

a. Watt Metre $93 \%$

b. Software $9 \%$

The disparity in percentage ranges generated by the watt results clearly indicated that the two sources were using different methods of data capture. As an example, the $84 \%$ range disparity attributed to video conferencing is a result of two factors. Firstly, the rapidity of content switching driving the watt requirement changes, as people interact via audio, video and screen presenter ownership. Secondly, the 
likelihood that only one of the two methods of measurement is able to keep pace. In order to substantiate the hypothesis, the method of watt data capture was examined for both the watt meter and the software.

As expected, the watt meter updated the change in power draw $(\mathrm{W})$ in real time as the user switched tasks, rising and falling as applications, video calls and web pages were opened, utilised and closed or left to rest. Monitored by filming the changes for two hours during a working day, it was noted that the watt metre $W$ value altered on average every three seconds as content interaction or focus changes. Comparatively, the Lakeside software reports measurements every five seconds obtaining power and energy consumption data by querying the hardware bios counters. The data points are then reported as an average power rating in Watts $(\mathrm{W})$ and a total energy consumption figure in kilowatt-hours (kwh) for consecutive ten minute periods during 'on time'. As such, it is true to state the following:

- For a single data capture conducted at 5 second intervals by the software, the watt meter will between 1 or 2 power $(\mathrm{W})$ readings. As such the regularity of data snapshot by the watt meter is feasibly 2:1 compared to the software.

- For each ten-minute average watt measurement reported by the software, the watt meter will have conducted a minimum of 200 calculations compared to the software's 120 readings

Consequently, it is reasonable to state that the software undertakes approximately $40 \%$ less $\mathrm{W}$ readings per day than the watt metre and this may cause increased margins of error if the components being measured are subject to content switching. As an example, during the 15-hour non-interactive period this had no effect as the power requirements did not fluctuate during the 3 second watt metre reading internal and the 5 second software interval. However, during the 9-hour active period the rapidity of power fluctuation driven by content switching caused the resulting $\mathrm{kWh}$ calculate to increase in disparity by a further $17 \%$ when compared to the inactive period. As the 'active on time' period experienced during day 8 represented $37.5 \%$ of the 24 -hour period, the overall disparity was increased by $7 \%$ to $+53 \%$, registering energy consumption of $0.478 \mathrm{kWh}$ by the software versus $0.313 \mathrm{kWh}$. As content switching is random with no day exactly matching another in tasks undertaken or duration it was deemed highly unlikely that examining whether the duration (percentage) of 'on time' would uniformly affect the kWh disparity. As Fig. 6 highlights this was proven to be the case as the lines generated by the on time and kWh disparity do not track one another and instead often cross over with one value exceeding the other.

As an example, days 23,27 and 30 all registered $52 \%$ on time, yet they have an energy consumption disparity between the software and the watt metre of $49 \%, 51 \%$ and $56 \%$ accordingly. In the first two examples the results appear promising that there is a correlation, however the third day questions the validity of the statement. Examining the on time results, notes and calendars for the three days, reveal that days 23 and 27 were spent working on research documents for the majority and therefore similar tasks were undertaken explaining the uniformity of the disparity in both on time and energy consumption. However, day 30 was spent viewing online training videos and participating in conference calls. Consequently, the tasks undertaken were evidently driving up the disparity due to the rapidity of content switching, despite the identical on time. As such, it is fair to state that whilst the active on time certainly 
influences the overall kWh measurement it is the duration of time spent during this mode undertaking specific tasks that dictate the range of increased over estimation.

To summarise the findings of the accuracy test, it is clear that the software is with substantial error in relation to measuring notebook energy use. Therefore, without compensatory measures being introduced to the calculations to generate concomitant GHG values for the proposed application, the emissions reporting will also be incorrect.

As the experiment identifies there are four specific factors that are causing the inaccuracy:

- A $46 \%$ uniform over reporting of kWh energy consumption during 'on time'

- An average additional $5 \%$ over reporting of kWh energy consumption during 'on time' generated by user content switching outpacing the measurement intervals

- A zero kWh value measured during 'off mode'

- Zero on time recording during 'sleep mode' causing minor associated energy consumption to be excluded

These findings were discussed in depth with the analytics software manufacturer in an attempt to validate the causes suggested by the results. The engineering experts suggested that the uniform over reporting was most likely due to the fact that the software algorithmic tables that are used for component energy consumption had not been updated for several years. They explained that when the analytics software was originally conceived the tables were based upon mechanical hard drives. As the device used in the test had a solid state hard drive which would require less watts to power then this would cause the erroneous but uniform disparity. They accepted that the additional $5 \%$ over reporting due to content switching causing a lag in results due to the real time reporting of the watt meter and the software would be an issue during active user time. The zero kWh value measurement during off mode and the zero on time during sleep mode were also accepted as a minor issue that could not be overcome. The positive response was that based upon this research, Lakeside would re-examine their algorithms for component parts and bring them up to date to cope with the introduction of SSD storage and similar modern innovation. Doing so may overcome the main issue of the $48 \%$ over reporting although this would require further research.

\section{Summary}

The objective to test the feasibility and accuracy of a newly proposed analytics software method to capture both EUC device asset and use profile data regardless of scale and mobility were achieved by the field experiment. All of the key data required to complete the Kawamoto et al data flow was captured during the 30-day measurement period including quantity, type, model and user plus power draw and on time. Doing so offers a consolidated approach to the practice, removing the need for two separate methods. As an example, without analytics, survey or asset management software is required to capture asset profile data and a watt metre required for every device to enable power draw and on time results. 
Consequently, the proposed approach reduces complexity associated with cross referencing the two sources as the dashboard and .xls extract structures the data in one single format. Additionally, as $86 \%$ of global EUC devices are now mobile, the analytics software removes the logistics issues associated with the placement and use of watt metres that causes organisations to avoid the direct measurement of EUC energy consumption. Data quality related to the asset profile experienced issues related to several fields. As described, role description for $70 \%$ of employees were omitted, although upon examination, incomplete information fields in the active directory were noted as the cause and as such for future use the issue is rectifiable. Similarly, $21 \%$ of devices could not be identified by location due to possible IP masking. As location data is essential to the generation of scope 2 concomitant GHG emissions values that in accordance with accounting protocol must be neither under nor over the actual quantities, this aspect requires attention to improve accuracy. However, these two limitations arguably become insignificant due to the fact that one of the ten categories of EUC devices, monitors, are simply not captured for asset nor use profile by the software. To test the impact of such an oversight, a 24" Acer B8 monitor was measured for 30 days in the workplace by this research using a watt meter. The electricity consumption per business day (9-5pm) was $0.096 \mathrm{kWh}$ equating to $1.92 \mathrm{kWh}$ for the twenty business days experienced during the field experiment's time horizon. As 157 monitors were noted by the analytics software as connected during the same period the unmeasured energy could be as high as $293.76 \mathrm{kWh}$, equivalent to $19 \%$ of the total energy captured by the analytics software. Considering too that ultimately the control user unearthed inaccuracies of $48 \%$ over estimation by the analytics software due to outdated

algorithms, then the impact would actually represent the exclusion of closer to $35 \%$ if employees regularly use the supplied monitors. To overcome the issue, the placement of watt metres between each monitor is technically feasible as these types of devices are not mobile and can remain connected to the power source. Subsequent data could be automatically supplied back to a master server by data loggers and compiled to add to the mobile and desktop computing data. However, undertaking such a task reintroduces the logistics issues that cause companies to avoid the practice in the first instance and as such may prove counterintuitive.

\section{Conclusion}

Whilst the asset data relating to EUC devices can be improved as discussed, the current exclusion of monitors from the data capture process and the inaccuracy of the use profile data indicate that the proposed solution overcomes scale and mobility issues at the cost of inclusion and accuracy. As EUC device energy consumption measurement is undertaken for several purposes certain aspects of the capabilities may prove useful whereas the findings may preclude the approach from use. As an example, if an organisation wishes to use analytics to support a sustainable device procurement programme then the method may be of worth. The rationale being that whilst inaccurate to an average of $48 \%$ in relation to electricity consumption, the software does have the ability to identify low average power draw results across the selected period. As such a stacked ranking of energy efficient devices could be compiled and fed back to procurement teams as supplementary information to current benchmark results such as the Energy Star TEC. However, in comparison, if the analytics method is to be used to generate use phase 
data for either product carbon footprint reporting or mandatory emissions reporting then it would prove inappropriate due to the omission of monitors and the over reporting of power draw averages. Contrarily, if the method is to be used within mobile only environments then it is reasonable to suggest that the results determine that the margin of error is reduced by $107 \%$ from $155 \%$ experienced by methods such as TEC based quantification. Despite this positive aspect and a pragmatic conclusion suggests that whilst the analytics method exhibits capabilities to overcome barriers such as scale and mobility, to support future widespread adoption all types of devices must be included and the algorithms used to generate specific power draw values must be corrected to achieve more accurate and ultimately compliant concomitant GHG use phase results.

\section{Limitations And Recommendations}

It is recognised that the control user was conducted on one notebook and a wider experiment with increased numbers of devices, brands and operating systems is suggested in order to further improve the comparative results. The rationale being that where mechanical hard drives exist in legacy equipment the software may prove more accurate. It is also noted that the analytics use profile data proved highly accurate and as such generates patterns of working hours for the subject organisation. This creates a feasible recommendation to advance the process of EUC energy consumption that accounts for the active operational mode. Firstly, if specific models of devices within an organisation can be measured by an accurate watt meter for a number of business days then patterns of electricity consumption by both vertical and role based use could be formed. Applying this as an hourly electricity consumption value to the analytics use profile by user would then arguably form an accurate value for the energy consumption and concomitant emissions. As such, it is recommended that in conjunction with improvements to algorithms undertaken by the software vendor, further research to triangulate measured energy consumption with on time should be explored.

\section{Declarations}

\section{Acknowledgements}

Frederik Dahlmann, Associate Professor of Strategy and Sustainability at the University of Warwick, Warwick Business School for ongoing co-supervision, and support.

Rob Procter, Professor of Social Informatics at the University of Warwick for ongoing co-supervision, and support.

Mike Schumacher, CEO and Founder, Lakeside Software

David Taylor, Sales Director, Lakeside Software

\section{Data Availability Statement}


The majority of data generated or analysed during this study are included in this published article. Additionally, a full copy of all datasets generated during and/or analysed during the current study are available from the corresponding author on reasonable request.

\section{References}

1. Andrae, A. S. G, Andersen, O. (2010), 'Life cycle assessments of consumer electronics - are they consistent?' Int J Life Cycle Assess 15 (8), 827-836

2. Andrae, A. S. G., and Edler, A.T., (2015). 'On global electricity usage of communication technology: trends to 2030.' Challenges 6, 117e157.

3. Andre, H., Ljunggren Soderman, M., Nordelof, A. (2018), 'Resource and environmental impacts of using second-hand laptop computers: A case study of commercial reuse'. Gothenburg, Sweden: Chalmers University of Technology.

4. Apple, (2021). 'Your product's environmental report card.' Cupertino, USA.

5. Arushanvan, Y., Ekener-Petersen, E., Finnveden, G. (2014), 'Lessons learned - review of LCAs for ICT products and services'. Amsterdam: Comput Ind.

6. Atlantic Consulting and IPU. (1998), 'LCA study of the product group personal computers in the EU Eco-label Scheme LCA study (Version 1.2). EU Eco-labels for personal computers'. Atlantic Consulting and IPU

7. Bakker, C., Wang, F., Huisman, J., den Hollander, M., (2014), Products that go round: exploring product life extension through design'. Amsterdam: J. Clean. Prod.

8. Bekaroo, G., Bokhoree, C., Pattison, C. (2014), 'Power Measurement of Computers: Analysis of the Effectiveness of the Software Based Approach'. New Delhi, India: Int. j. emerg. technol. adv. eng.

9. Belkhir, L., and Elmeligi, A. (2017) 'Assessing ICT global emissions footprint: Trends to 2040 \& Recommendations'. Oxford: Science Direct

10. Carbon Footprint. (2020), '2020 Carbon Footprint Country Specific Grid Greenhouse Gas Emissions Factors.' Hampshire: Carbon Footprint

11. Cartledge, C. (2008), 'Energy Impacts of ICT at the University of Sheffield, Bradford: SustelT, July, 2008.' Bristol: SustelT

12. Choi, B., H. Shin, S. Lee, and T. Hur. (2006), 'Life cycle assessment of a personal computer and its effective recycling rate'. Int J Life Cycle Assess 11(2): 122-128.

13. Cooper, D. R., Gutowski, T.G. (2017), 'The environmental impacts of reuse: a review'. J. Ind. Ecol.

14. Data Reportal. (2020), 'Global Digital Overview'.

15. Dell. (2021), 'Select Product Carbon Footprint Assessments'. Roundrock, Texas.

16. Deng, L., Babbitt, C.W., Williams, E.D. (2011), 'Economic balance hybrid LCA extended with uncertainty analysis: case study of a laptop computer'. Amsterdam: J. Clean. Prod. 
17. Department for Business Energy and Industrial Strategy and Department for Environment Food and Rural Affairs. (2021), 'UK Government GHG Conversion Factors for Company Reporting'. London: Crown Copyright

18. Duan H, Eugster M, Hischier R et al (2009) Life cycle assessment study of a Chinese desktop personal computer. Sci Total Environ 407:1755- 1764

19. Energy Star. (2017), 'Energy Star Program Requirements for Computers'.

20. Energy Star (2021) 'Product finder, product, certified computers, results.'

21. Finnveden, G., Arushanyan, Y., Brandao, M, 2016. 'Exergy as a measure of resource use in life cycle assessment and other sustainability assessment tools'. Basel, Switzerland: Resources MDPI

22. Gartner. (2019), ' 6 Ways the Workplace Will Change in the Next 10 Years'. Arlington, VA: Gartner Inc.

23. Gartner, (2021). 'Gartner Says Worldwide PC Shipments Grew 10.7\% in Fourth Quarter of 2020 and $4.8 \%$ for the Year.' Arlington, VA: Gartner Inc.

24. Global e-Sustainability Initiative. (2008), SMART 2020: Enabling the low carbon economy in the information age. Figure 3.1 The global footprint of PCs - desktops and laptops: 19. Brussels: GESI

25. Global e-Sustainability Initiative. (2012), 'SMARTer 2020: The Role of ICT in Driving a Sustainable Future.' The ICT Industry's GHG Emissions: 22. Brussels: GESI

26. Global e-Sustainability Initiative. (2015), '\#SMARTer2030 ICT Solutions for 21st Century Challenges.' Executive Summary: ICT Solutions for 21st Century Challenges: 8. Brussels: GESI

27. Global e-Sustainability Initiative. (2019), 'Digital with Purpose: Delivering a SMARTer2030'. Brussels: GESI

28. Greenblatt, J. B., Stacy Pratt, Henry Willem, Erin Claybaugh, Louis-Benoit Desroches, Bereket Beraki, Mythri Nagaraju, Sarah K. Price and Scott J. Young. (2013), Field data collection of miscellaneous electrical loads in Northern California: Initial results.' Ernest Orlando Lawrence Berkeley National Laboratory research paper: 4-5

29. Haque, N. (2020), 'The Life Cycle Assessment of Various Energy Technologies'. Australia: Science Direct

30. Hart, J. (2016), 'Carbon Emission Implications of ICT Reuse at the University of Edinburgh'. University of Edinburgh Department for Social Responsibility and Sustainability

31. Hopkinson, L and James, P. (2009), 'Energy and Carbon Impacts of ICT User Guide for the SustelT Footprinting Tool'. Bristol: SUSTEIT

32. Hosni, M.H., Jones, B.W., and Xu, H. (1999), 'Measurement of Heat Gain and radiant/Convective Split from Equipment in Buildings, Final Report'. ASHRAE Research Project 1055-RP, March.

33. HP Inc. (2021), 'Product Carbon Footprint Reports: Notebooks'. Palo Alto: HP Inc.

34. Intellect. (2016), 'Evaluating the carbon impact of ICT or The answer to life, the universe and everything. Understanding the limitations of LCA-based carbon footprinting methodologies'. London: Intellect

35. International Energy Agency. (2019), 'Global Energy \& CO2 Status Report 2019'. Paris, France. 
36. International Energy Agency. (2021a), 'Data Centres and Data Transmission Networks'. Paris, France.

37. International Energy Agency. (2021b), 'Aviation'. Paris, France.

38. Intergovernmental Panel on Climate Change. (2018), 'Global warming of 1.5oC'. Switzerland: IPCC

39. IVF Industrial Research and Development Corporation. (2007), 'European Commission DG TREN Preparatory studies for Eco-design Requirements of EuPs. IVF Report 07004. Laptop used in office.' Table 91, 93 \& 97

40. JISC. (2019), 'SustelT ICT Energy and Carbon Footprinting Tool'

41. Kansel, A. (2010): Joulemeter: Computational Energy Measurement and Optimization. Redmond, WA, USA: Microsoft.

42. Karpagam, S. and Yung, W. K. C. (2017), 'Life cycle assessment study of an integrated desktop device: comparison of two information and communication technologies: Desktop computers versus all-in-ones'. J. Clean. Prod.

43. Kawamoto, K., J. Koomey, B. Nordman, R. Brown, M.A. Piette, M. Ting, M., and Meier, A., (2001), 'Electricity Used by Office Equipment and Network Equipment in the U.S.: Detailed Report and Appendices' LBNL-45917: 3

44. Kemna, R.,M. van Elburg, W. Li, and R. van Holsteijn. (2005). Methodology study of energy-using products. Delft, Netherlands and Brussels, Belgium: VHK and European Commission.

45. Kim S, Hwang T, Overcash M (2001) Life cycle assessment study of a colour computer monitor. Int J LCA 6:35-43.

46. Komor, P. (1997), 'Space Cooling Demands from Office Plug Loads', ASHRAE Journal, December, pp. 41-44.

47. Koomey, J., Cramer, Piette, M.A., and Eto, J. (1995) Efficiency Improvements in U.S. Office Equipment: Expected Policy Impacts and Uncertainties. LBNL, 1995. LBNL-37383

48. Kunz, M. (1997), 'Energy Consumption of Electronic Network Components', Report of the 'Electricity' Research Programme, Swiss Federal Office of Energy, Berne, Switzerland.

49. Lenovo. (2021), 'ECO Declarations and Product Carbon Footprint Information Sheets'. Quarry Bang: Hong Kong.

50. Lu L, Wernick IK, Hsiao TY et al. (2006), 'Balancing the life cycle impacts of notebook computers: Taiwan's experience. Resources, Conservation and Recycling.' 48:13-25

51. Malmodin, J., Bergmark, P., Lunden, D., (2013). The future carbon footprint of the ICT and E\&M sectors. In: On Information and Communication Technologies.

52. Microsoft. (2020), 'Eco Profiles.' Redmond: USA

53. McKinsey Global Institute (2021), 'What's next for remote work: An analysis of 2,000 tasks, 800 jobs, and nine countries'. New York: McKinsey

54. McManus, T. (2002), 'Moore's Law and PC Power'. Tulane Engineering Forum

55. Norford. L. K., Rabl, A., Harris, J., and Roturier, J. (1988). 'The sum of megabytes equals Gigawatts: Energy Consumption and Efficiency of Office PCs and Related Equipment.' In Proceedings of the 
ACEEE 1988 Summer Study on Energy Efficiency in Buildings. Volume 3, pp. 3.181-3.196. American Council for an Energy Efficient Economy, Washington DC.

56. PE International. (2008), 'Environmental footprint of ICT equipment in manufacture, use, and end-oflife. Brussels, Belgium: Presentation held at ECOC

57. Peters, J., Weil, M. (2016), 'A critical assessment of the resource depletion potential of current and future lithium-ion batteries. Switzerland: Resources

58. Prakash, S., Kohler, A., Liu, R., Stobbe, L., Proske, M., Schischke, K. (2016), 'Paradigm Shift in Green IT - Extending the life-times of computers in the public authorities in Germany. New Jersey: IEEE

59. Rigamonti, L., Falbo, A., Zampori, L., Sala, S. (2016), 'Supporting a transition towards sustainable circular economy, sensitivity analysis for the interpretation of LCA for the recovery of electric and electronic waste'. Int J Life Cycle.

60. Rorbech, J. T., Vadenbo, C., Hellweg, S., Astrup, T.F. (2014), 'Impact assessment of abiotic resources in LCA: quantitative comparison of selected characterisation models'. Environ. Sci. Technol.

61. Roth, K., Goldstein, F, and Kleinman, J., (2002) Energy Consumption by Office and Telecommunications Equipment in Commercial Buildings--Volume I: Energy Consumption Baseline. Washington, DC: Prepared by Arthur D. Little for the U.S. Department of Energy. A.D. Little Reference no. 72895-00.

62. Sahni, S., Boustani, A., Gutowski, T.G., Graves, S.C. (2010), 'Reusing personal computer devices Good or bad for the environment?' New Jersey: Proceedings of the 2010 IEEE International Symposium on Sustainable Systems and Technology.

63. Schischke, K., Kohlmeyer, R., Griese, H., Reichl, H., (2003), 'Life cycle energy analysis of PCs Environmental consequences of lifetime extension through reuse'. 11th Lausanne: LCA Case Studies Symposium

64. Socolof ML, Overly JG, Geibig JR (2005) Environmental life-cycle impacts of CRT and LCD desktop computer displays. J Clean Prod 13:1281-1294

65. Socolof, M.L., Overly, J. G., Kincaid, L. E., and Geibig, J. R. (2017), 'Desktop Computer Displays: A LifeCycle Assessment'. Tennessee, USA: University of Tennessee Center for Clean Products and Clean Technologies

66. Sonderegger, T., Dewulf, J., Fantke, P., de Souza, D.M., Pfister, S., Stoessel, F., Verones, F., Viera, M., Weidema, B., Hellweg, S. (2017), 'Towards harmonising natural resources as an area of protection in life cycle assessment.' Int J Life Cycle.

67. Statistica Research Department. (2020). 'Global shipment of tablets, laptops and desktop PCs 20102023'. Amsterdam: SRD

68. Statistica Research Department. (2021). 'PC unit shipments worldwide from 2019 to 2025, by type.' Amsterdam: SRD

69. Steen, B.A. (2006), 'Abiotic resource depletion - different perceptions of the problem with mineral deposits'. Int J Life Cycle. 
70. Subramanian, K., Yung, W.K.C. (2016). 'Review of life cycle assessment on consumer electronic products: developments and the way ahead.' Critical Review of Environmental Science and Technology. 46 (18), 1441-1497.

71. Sutton-Parker, J. (2020), 'Determining end user computing device Scope 2 GHG emissions with accurate use phase energy consumption measurement'. 1877-0509. Amsterdam, the Netherlands: Science Direct, Elsevier B.V.

72. Teehan, P., Kandlikar, M., (2012). 'Sources of variation in life cycle assessments of desktop computers. J. Ind. Ecol. 16 (no. S1), S182eS194.'

73. Tekawa, M., Miyamoto, S., Inaba, A. (1997), 'Life cycle assessment; an approach to environmentally friendly PCs'. Proc IEEE International Symposium of Electronic Environment, May 5-7, San Francisco, CA, 125-130

74. Thiebaud, E., Hilty, L.M., Schluep, M., Widmer, R., Faulstich, M. (2017), 'Service lifetime, storage time and disposal pathways of electronic equipment: A Swiss case study.' J. Ind. Ecol.

75. United Nations Environment Programme. (2019), 'Emissions Gap Report'. Table ES1 Page 8.

76. Vadenbo, C., Hellweg, S., Astrup, T. F. (2017), 'Let's be clear(er) about substitution: a reporting framework to account for product displacement in life cycle assessment.' Yale: J. Ind. Ecol.

77. Williams, E. (2004), 'Energy intensity of computer manufacturing: Hybrid assessment combining process and economic input-output methods'. Environ. Sci. Technol.38:6166-6174

78. Wolf, M. A., Chomkhamsri, K., Brandao, M., Pant, R., Ardente, F., Pennington, D. W., Manfredi, S., de Camillis, C., Goralczyk, M. (2010), ILCD handbook general guide for life cycle assessment'.

79. World Business Council for Sustainable Development and World Resources Institute. (2004), 'The Greenhouse Gas Protocol. A Corporate Accounting and Reporting Standard'. Geneva, Switzerland and New York, USA.

\section{Figures}




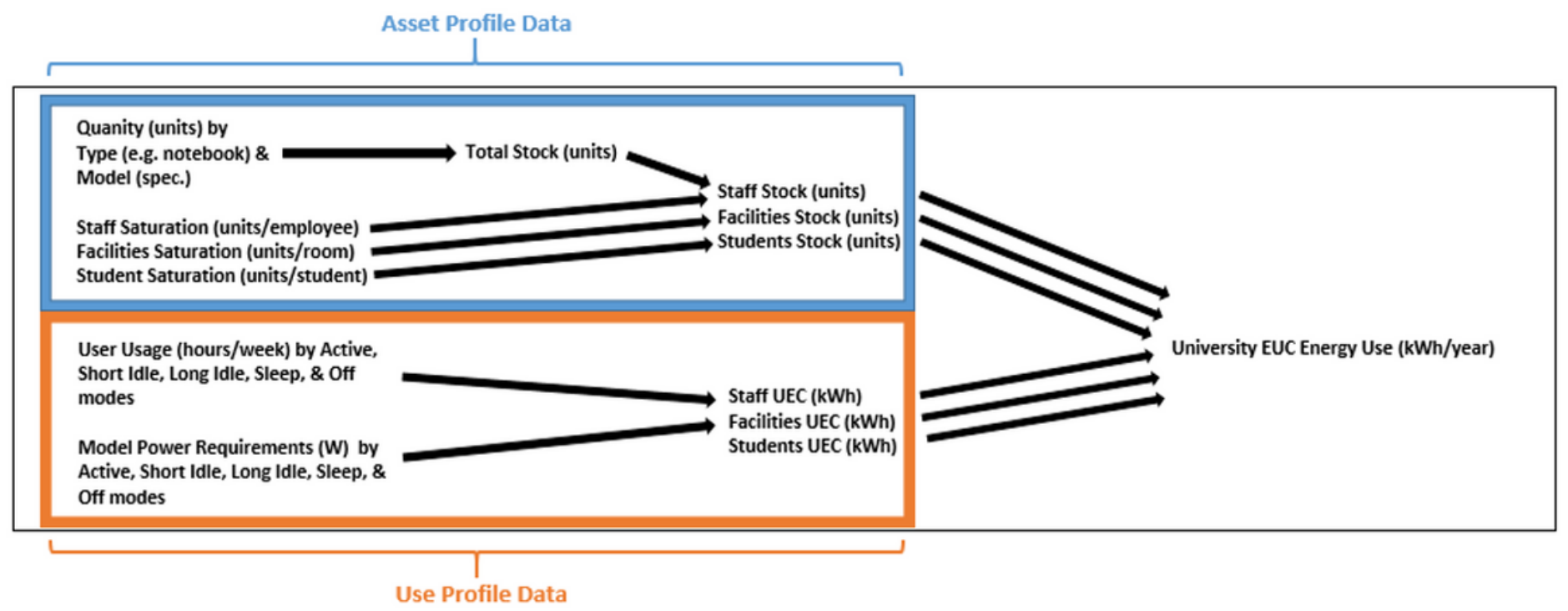

\section{Figure 1}

Modified Kawamoto et al (2001) and Roth et al (2002) EUC kWh data flow

\begin{tabular}{|l|l|l|l|l|l|l|l|l|}
\hline $\begin{array}{l}\text { Computer } \\
\text { Name }\end{array}$ & $\begin{array}{l}\text { Power } \\
\text { Av. (W) }\end{array}$ & $\begin{array}{l}\text { On Time } \\
\text { Observed } \\
(\%)\end{array}$ & $\begin{array}{l}\text { Elec } \\
\text { Monthly } \\
(\mathbf{K W H})\end{array}$ & Manufacturer & Model & Chassis & $\begin{array}{l}\text { Country } \\
\text { Location }\end{array}$ & Role \\
\hline Computer 1 & 17 & 15.9 & 2 & Dell Inc. & $\begin{array}{l}\text { Latitude } \\
\text { E7450 }\end{array}$ & Laptop & NL & Not collected \\
\hline Computer 2 & 54 & 42 & 17 & Dell Inc. & XPS 15 9570 & Notebook & US & Not collected \\
\hline Computer 3 & $\begin{array}{l}\text { Not } \\
\text { collected }\end{array}$ & $\begin{array}{l}\text { Not } \\
\text { collected }\end{array}$ & $\begin{array}{l}\text { Not } \\
\text { collected }\end{array}$ & Not collected & Not collected & $\begin{array}{l}\text { Not } \\
\text { collected }\end{array}$ & US & $\begin{array}{l}\text { Technical } \\
\text { Support }\end{array}$ \\
\hline Computer 4 & 47 & 70.5 & 24 & Dell Inc. & XPS 13 9370 & Notebook & US & Not collected \\
\hline Computer 5 & 10 & 21.4 & 2 & Apple Inc. & Not collected & Laptop & Not collected & Not collected \\
\hline Computer 6 & 39 & 33.3 & 9 & Dell Inc. & XPS 13 7390 & Notebook & US & Not collected \\
\hline Computer 7 & 32 & 69.6 & 16 & Dell Inc. & XPS 13 9370 & Notebook & US & Not collected \\
\hline Computer 8 & 55 & 31.5 & 13 & Dell Inc. & XPS 13 9370 & Notebook & US & Not collected \\
\hline Computer 9 & 30 & 91.7 & 21 & $\begin{array}{l}\text { Hewlett- } \\
\text { Packard }\end{array}$ & $\begin{array}{l}\text { HP EliteBook } \\
\text { Folio 1040 G1 }\end{array}$ & Notebook & IL & Not collected \\
\hline Computer 10 & 34 & 24.4 & 6 & HP & $\begin{array}{l}\text { HP EliteBook } \\
840 \text { G6 }\end{array}$ & Notebook & PL & Not collected \\
\hline
\end{tabular}

Figure 2

Analytics asset and use profile data extract 


\section{EUC $k$ Wh consumption \& GHG by country}

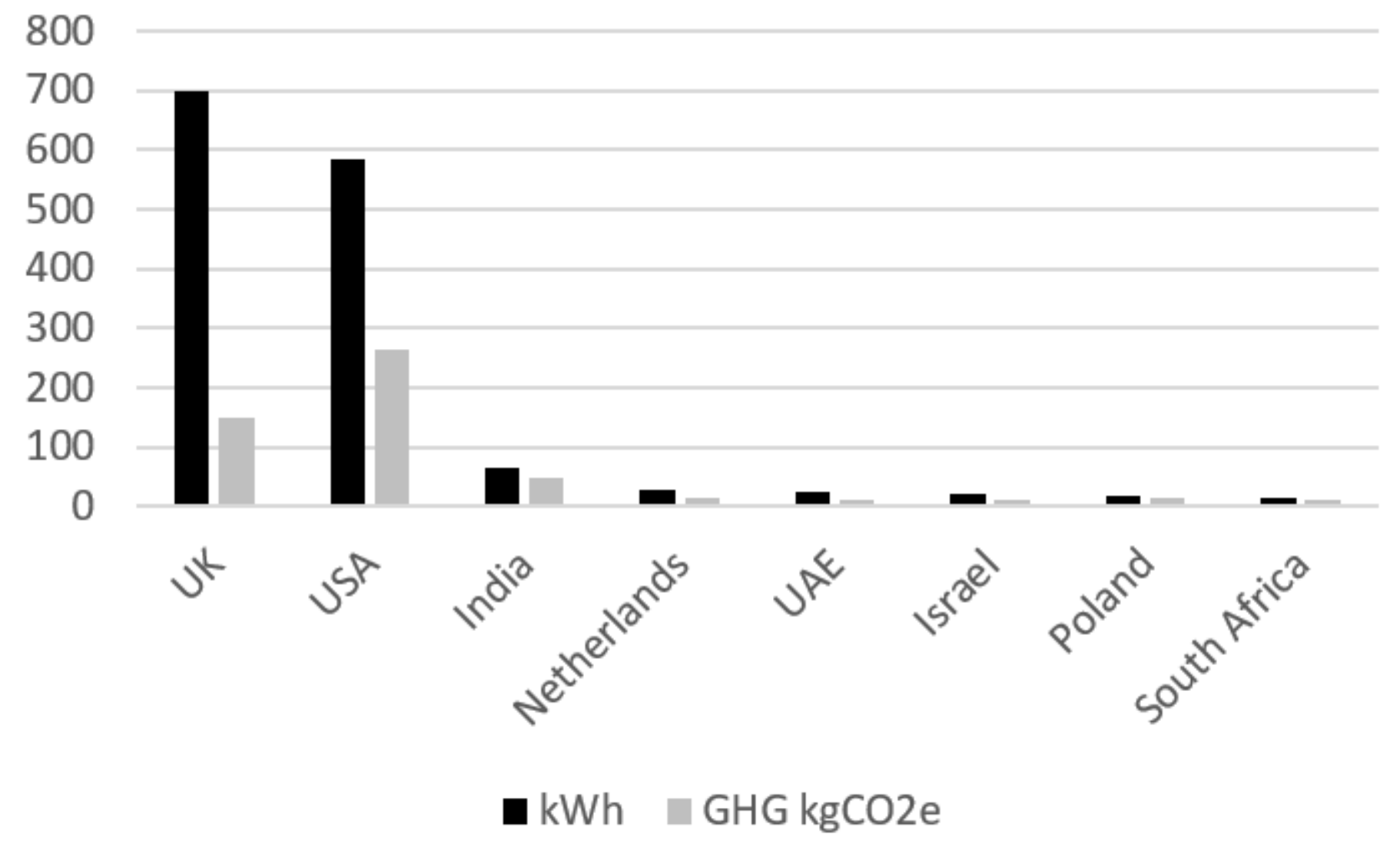

Figure 3

EUC use phase electricity consumption (kWh) \& GHG emissions (CO2e) by country

kWh Measurement By Source

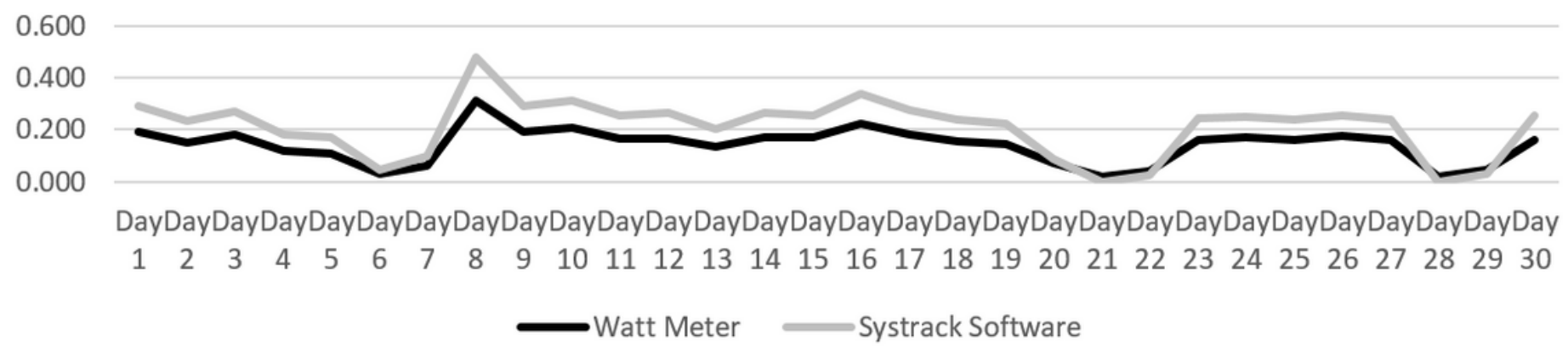

Figure 4 
Energy Consumption ( $\mathrm{kWh}$ ) Measurement by Source (watt metre and software)

\section{Content Switching Watts by Source}

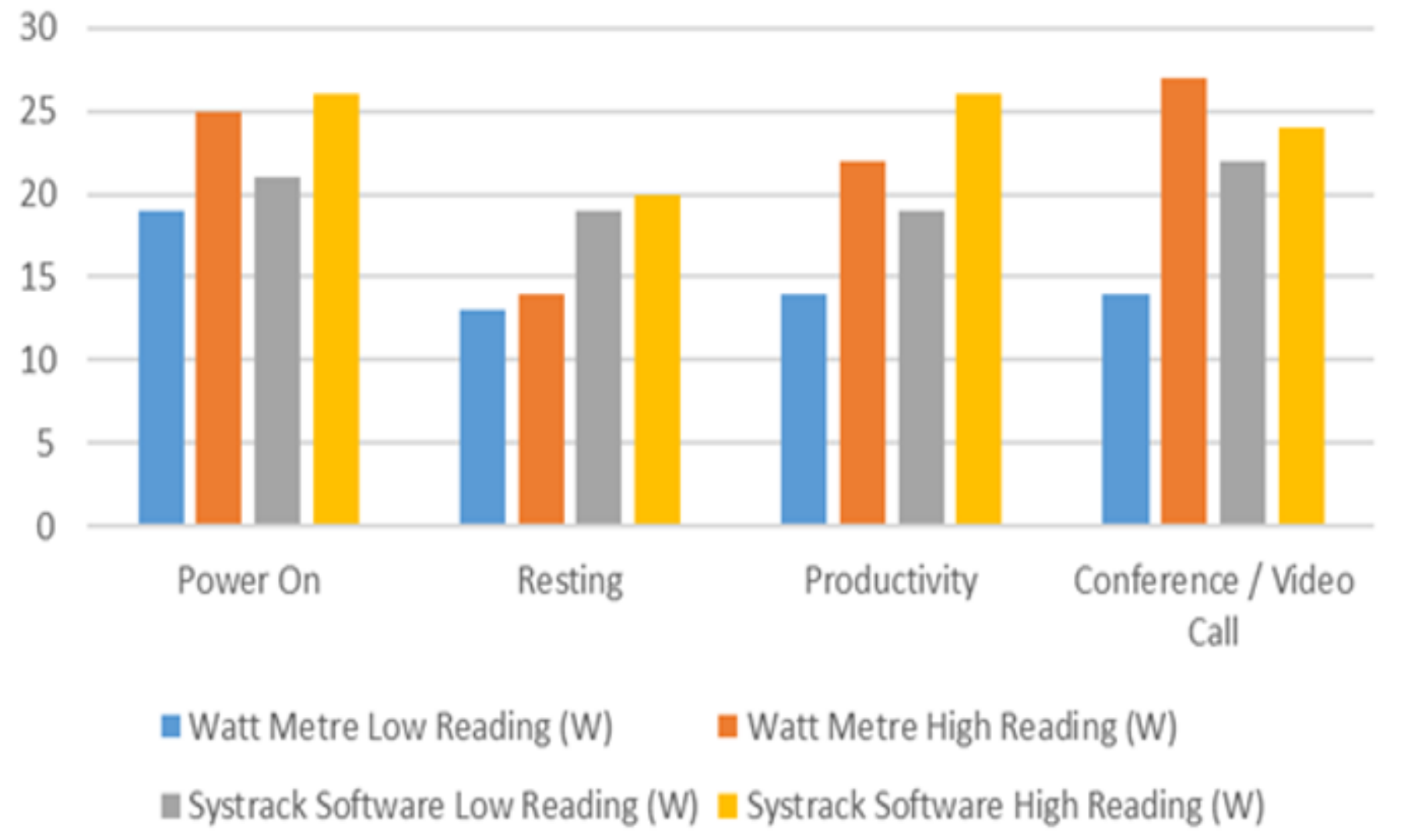

Figure 5

Task impact of Watts Required

\section{kWh \& On Time \% Disparity Correlation}

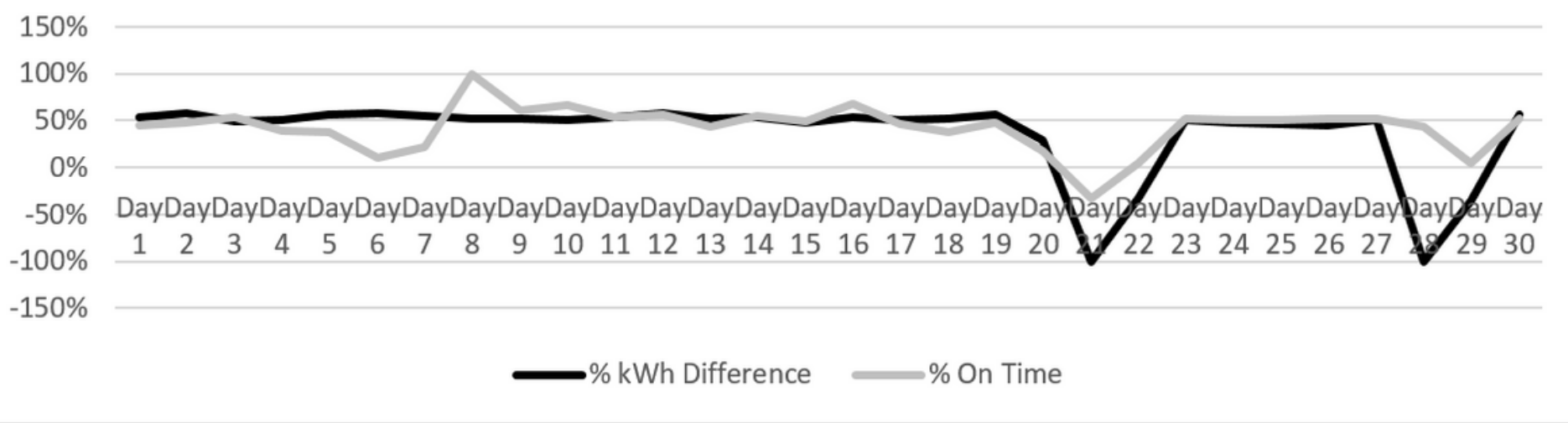

\section{Figure 6}


On time vs kWh disparity

\section{Supplementary Files}

This is a list of supplementary files associated with this preprint. Click to download.

- 2021CTaEPJSPGraphicforAnalyticsResearch.jpg 